\title{
Chapter 8 \\ Corporate Social Responsibility (CSR) and the 2030 Agenda in the Framework of New Trends in Tourism and Hotel Companies' Performance
}

\author{
Raquel García Revila \\ Universidad a Distancia de Madrid, Spain \\ Olga Martinez Moure \\ Universidad a Distancia de Madrid, Spain
}

\begin{abstract}
Sustainable tourism refers to those tourism activities that respect the natural, cultural, and social environment and the values of a community, which allows it to enjoy a positive exchange of experiences between residents and visitors, where the relationship between the tourist and the community is fair and the benefits of the activity are evenly distributed, and where visitors have a truly participatory attitude in their travel experience. One of the main keys to sustainable tourism is the involvement of the visitors and the host and local community.
\end{abstract}

\section{INTRODUCTION}

Today, tourism activity constitutes a sector that has a substantial weight in the global economy of a country. That is, income from spending by tourists in countries contributes significantly to the balance of payments, especially in developing countries. The contribution that tourism makes to a country's economy as a consequence of its ability to generate foreign exchange is usually analyzed. This is evident when the income generated by this concept is compared with other parts of the balance of payments, generally with imports, services of the country's external debt with exports.

DOI: $10.4018 / 978-1-7998-4543-0 . c h 008$

Copyright $\odot$ 2020, IGI Global. Copying or distributing in print or electronic forms without written permission of IGI Global is prohibited. 
In the case of Spain, tourism is very important since it has been marked by a very important evolution, which has led to a change of scenery: the tourism passed from a developmental model to a very environmentally friendly (the current paradigm). It is at this stage, precisely, where acquires a specific weight the corporate social responsibility, which is described as a type of direction that planned activities of organizational nature by taking into account the impact on the environment and on the local community.

Spain participates in various international programs to promote sustainable tourism, among them are the FITUR Green Sustainability and Tourism Forum. Among the organizers of this event is the Technological Hotel Institute, a Spanish organization promotes the efficiency and sustainability of companies linked to the hotel and tourism industry. The result is translated into Spanish tourist companies with a marked ecological and sustainable profile. Also, for the protection of its wetlands, Spain participates in the Ramsar Convention or Convention on Wetlands of International Importance which includes more than 70 Spanish natural spaces. They are aquatic bird habitats in which they try to maintain their ecosystem and guarantee their future.

In this chapter it will explain, in a very succinctly way, how has been the evolution that has characterized the most hotel and tourist companies in Spain. Mainly, this work will be focusing specifically on the current situation, which, as it was explained in previous lines, is clearly marked by corporate social responsibility. This way of understanding the tourism business acquires its own dimension at a time of economic and sociological changes as important as the current, also strongly influenced by the international crisis which has seriously affected Spain. Tourism businesses, more than any other organization, have adapted to the turbulent changes produced in this changing scenario, configured as a model to follow for the good practice they have shown in the conduct of their business.

In fact, it can be ensured that one of the strategic lines and business of the hotel and tourist companies in general has been precisely environmental responsibility, which in tourism is framed by the sustainable tourism. It has not always been so, since in the recent past, the tourism phenomenon did not participate in the canons of sustainability and was joined, in many cases, with excessive town planning. Fortunately, this reality is part of the past and today we find a scenario of respect for the environment and commitment to the natural and cultural capital of the people.

Corporate social responsibility has recently been defined by the European Commission (2001) as "the responsibility of companies for their impact on society". This concept includes social, economic and environmental resources. The companies that decide to assume the social responsibility in their daily management, modifying the management of the company, the means of communication, of communication among others etc.) and on the other the need to measure and to reduce their environmental impacts.

In the Charter for Sustainable Tourism, approved by the World Tourism Organization, which marked a before and after, states in its first principle: Tourism development shall be based on criteria of sustainability, which means that it must be ecologically bearable in the long term, as well as economically viable, and ethically and socially equitable for local communities. (...) As a powerful instrument of development, tourism can and should participate actively in the sustainable development strategy. A requirement of sound management of tourism is that the sustainability of the resources on which it depends must be guaranteed (UNWTO, 1995).

Sustainable tourism refers to those tourism activities that respect the natural, cultural and social environment and the values of a community, which allows to enjoy a positive exchange of experiences between residents and visitors, where the relationship between the tourist and the community Is fair and the benefits of the activity are evenly distributed, and where visitors have a truly participatory attitude in their travel experience. 
One of the main keys to sustainable tourism sustains that it is necessary the involvement of the visitors and the host and local community, so that this new conception of tourist practice have guaranteed future.

However, to understand the full dimensionality of sustainable tourism and how it has acquired naturalization, it is necessary to bring up the work of the Commission of the European Communities, which published a paper in 2001, where a strategy of sustainable development is established - not only for tourism, but development in general - for European countries.

All this critical consciousness - not recent, since enjoys a certain tradition - it also connects to corporate social responsibility. In this regard, the Green Book of the European Commission (2001) points out that the social responsibility of the employer could be defined as: Companies integrate social and environmental concerns in their business operations and in their interaction with their stakeholders on a voluntary basis. From this definition, derives the idea of establishing important environmental strategic lines in the shares of companies based in countries of the European Union.

The concern of the European Union for environmental responsibility, sustainable development and good management of tourism businesses, has been reflected, as we have already seen, in multiple documents. It should also be mentioned the Communication from the Commission to the Council, the European Parliament, the Economic and Social Committee and the Committee of the Regions (2003), which focused in particular on the guidelines to be followed by tourism in Member Countries to be considered sustainable. We quote textually some interesting lines in this regard:

- $\quad$ Sustainable tourism value also means optimizing employment and social benefits, i.e. the sector's enterprises implement the concept of corporate social responsibility.

- Regarding initiatives for encouraging the development and adoption of good practice in sustainable production throughout the European tourism sector and among its stakeholders, the Commission favors in particular promoting the principles of governance and fostering Corporate Social Responsibility (CSR) practices as a specific initiative within the European Multi-stakeholder Forum on CSR. Focusing on the enterprises of the sustainable value chain, in particular SMEs and micro-enterprises, this needs to involve, for implementation purposes, appropriate intermediaries to reach these enterprises.

- $\quad$ Open governance requires businesses to assume responsibility in conducting their operations in an economically viable manner that takes into account environmental and social issues.

- Major objectives regarding good private and public governance for sustainable tourism are, among others,: the integration of sustainable tourism development into overall economic, social and environmental development strategies; integrated sector policies and overall coherence across all levels; among the means to be employed are mentioned: the development and adoption of corporate responsibility reporting and sustainability accounting in both the public and private sectors; using Local Agenda 21 specifically for tourist destinations, including at regional level; the use of value chain and destination development monitoring and indicator systems; and the participation of citizens, both as consumers and in the work place.

- Better-quality and easily-accessible information on the environment and on practical matters helps shape opinions and thus individual tourists' decisions that support sustainability. The extension of the Community eco-label scheme to services started with the sub-sector of tourist accommodation, the first service sector for which ecological criteria were developed. Likewise, a wide uptake of the Community Eco-Management and Audit Scheme (EMAS) by the tourism sector 
to evaluate, report and improve environmental performance, together with rigorous and independently-verified environmental or sustainable development performance reports, is to be favored.

The various European institutions such as the European Commission are aware of national diversity that exists within the Union, being composed of countries with a particular culture and diverse traditions. Therefore, companies in each nation are embedded in the culture. Thus, European institutions, and, in a very specific and particular way, the Commission have established lines of action on corporate responsibility and respect for the environment, unifying them into a single consensus. That is, it always considers the peculiarity of each area and the global context of the Union. The White Paper states that anyone who polluter should pay. Textually, in the White Paper is contained the following sentence: Environmental liability aims at making the causer of environmental damage pay for remedying the damage that he has caused.

In this way, a tourism industry in which environmental responsibility and accountability are an inherent part of the commercialization of tourist services, it is possible to reduce negative impacts on the environment and on local cultures, particularly in areas of rich biodiversity, fragile ecosystems and communities vulnerable.

\section{METHODOLOGY}

The research goal is to analyze the evolution that have suffered tourism businesses, specifically in Spain, centering on the current situation, marked by Corporate Social Responsibility. For this aim, a global vision of tourism in Spain will be given in first place, including a brief summary of the importance of tourism in sustainable development at a global level, the context of sustainability explained internationally and characteristics of the current tourism organization in Spain. Then, an empirical study of the situation of Spain in the Global Compact and Global Reporting Initiative (GRI) agreement is realized. This empirical study consists on shown the evolution of the Global Compact Spanish companies and the number of Spanish companies reporting according to GRI over the years of study (2002-2012). Next, a regression function to predict the evolution of the Global Compact Spanish companies and the number of Spanish companies reporting according to GRI in the coming years are estimated. Finally, the importance of tourism organizations is mentioned as final reflection.

\section{THEORETICAL FRAMEWORK}

The focus on corporate social responsibility has been in the media in the United States since the 1990s. Since then, it has become a pillar of the arsenal of public relations campaigns of many corporations. In an ideal world, the common assumption is that corporations act in a socially responsible manner as a result of internally or externally motivated ethical obligations (Holcomb, Upchurch, \& Okumus, 2007).

To understand the centrality of Corporate Social Responsibility in tourism businesses and the situation in which we currently find ourselves, must be reviewed - albeit in a summarily way - who have been the most important authors who have created a theoretical corpus on this matter. Thus, it is necessary to quote Middleton (1998), who speaks in his scientific production, which factors they were that have led to tourism businesses to advocate and implement the principles of sustainability. He has not focused solely 
on these aspects, he has also spoken of the importance of reducing costs to reach business success, etc., but the idea is to emphasize the issue of sustainability, as the main theme of this chapter. Meanwhile, Porter and Van der Linde (1995) emphasize the importance of the proper use of natural resources and the constant search for quality. This is especially relevant in the case of hotels - although it is a constant factor for all companies and organizations. An example of how these theories impact on the new hotel management has been the change in the use of non-renewable nature resources by renewable resources. This has brought a benefit to the environment and hotel management.

Corporate social responsibility has been the result of growing interest among academics and practitioners. It has been seen as a philosophy and a policy that brings great benefits to the economy, society and the environment. This is through the idea that companies have broad goals beyond trade. This fact is usually a difficult task, however, the tourism industry seems to have particular and identifiable duties outside the business sphere, due to its close relationship with destination environments and societies that are facets of its products (Henderson, 2007). Corporate social responsibility activities carried out by tourism companies have a positive influence on their market value. Social initiatives for tourism not only generate social benefits for society directly, but also through commercial mechanisms through the increase of benefits that benefit the community, social action (Nicolau, 2008).

The use of sustainable and green buildings to house hotels has been another demonstration of this change of scenario, which calls for eco-efficiency. Nevertheless, for this new scenario solidifies and extends to the entire sector, it is necessary that the managers of the hotel organizations and entrepreneurs have a critical awareness of these issues. It is already a widely debated issue. For example, Ayuso (2005), Ayuso and Argandoña (2009), and Llull (2003) emphasize the importance of the entrepreneur to reach this eco-efficiency. In the same vein, staff awareness - directly linked to human resources becomes another important factor. Obviously, the environmental concerns of the entrepreneur can only have visibility as long as the public authorities at all levels have a disposition to care for their surroundings and environment - context that is occurring within Europe - establishing mandatory standards for environmental quality, grants for companies and organizations that perform best practices, pricing of natural resources as water, etc.

\section{THE IMPORTANCE OF TOURISM IN SUSTAINABLE DEVELOPMENT AT A GLOBAL LEVEL}

As a multiplicity of authors have expressed in recent times, sustainable development is the set of processes to achieve optimal and respectful management of natural resources. In addition, the sustainable development makes these natural resources more durable, with the aim that they are properly enjoyed by future generations. For this reason, tourism activities must always revolve around on sustainability criteria, i.e., long-term durability of the natural and cultural environment and commitment to renewable energies.

In summary, the objective of this - not so new - line of thinking is the preservation of cultural and environmental capital worldwide. Thus, tourism should contribute to sustainable development while preserving the traditions of the people and generating economic inputs that reversing to the local population. In addition, it is necessary to respect the loading capacity of the ground and be particularly respectful of fragile environments. In turn, must involve all participants in the process (visitors and host community) in solidarity so that tourism could be dynamic and always respectful by the two poles. 
The public authorities of each country should ensure that this can be fulfilled correctly and effectively - along with the establishment and promotion of suitable environmentally systems and with different tourism management studies. In the same vein, the Environment Program in Tourism of the United Nations points out that sustainable tourism must not only satisfy the needs of visitors, but also the receiving regions - the context in which the touristic experience develops - while future options are generated for the host community.

Precisely, with the aim that tourism is always a sustainable process becomes necessary to be made various codes and actuation systems of Corporate Social Responsibility, as indeed, is happening in Spain and in the countries of the European community. But of course, Corporate Social Responsibility is not only a concern in Europe. Rather, it is a worldwide concern in a collaborative level, in which Iberoamerican countries are quite involved and have hosted congresses and world level meetings on issues related to sustainability. It can be exemplified the case of the XVII Inter-American Travel Congress, which was developed in Costa Rica (specifically, in the city of San José) in 1997. This congress was characterized because Tourism Ministers approved the Declaration and Plan of Action for the sustainable development of tourism, and marking a before and after in sustainable tourism. This global meeting was called Declaration of San José and it states and emphasized the commitment of States to advocate for a respectful development based on tourism. The active role of tourism in the equal development of nations is also highlighted.

\section{THE CONTEXT OF SUSTAINABILITY EXPLAINED INTERNATIONALLY}

With current globalization, it is evident that it should be take into account the international political context. This, to understand the full depth that happens with business organizations in each country. This, if anything, becomes more intense in the case of organizations and tourism companies, because from the perspective of the UN (United Nations), tourism is set as one of the economic activities that move a greater amount of economic inputs at worldwide level. Furthermore, it is also a key activity to poverty alleviation in some depressed areas of the earth. That is why it has taken validity one famous phrase, which collects this idea very well: Tourism for the poor. In fact, says the Tourism Alliance Against Poverty (collaboration made between the International Centre for Responsible Tourism, the International Institute for Environment and Development and finally, the Institute for Overseas Development, Tourism for the poor can be defined as the kind of tourism whose benefits are aimed at increasing the quality of life of persons without resources.

In short, it is to combine tourism with community development. This is one of many examples that make visible the importance of tourism development to alleviate the inequalities in the world and the gap between rich and poor.

Sustainable development consists above all of giving people opportunities to influence their future, to claim their rights and express their concerns. The UN's long-term vision of global sustainability is to eradicate poverty, reduce inequality and make growth inclusive, and make production and consumption more sustainable, while tackling the effects of climate change and respecting others Planetary boundaries. Country economic policies and international economic relations are largely relevant to sustainable development. The revival and acceleration of development require a dynamic and supportive international economic environment, as well as policies decided at national level. The absence of any of these requirements will frustrate the development process. A favorable external economic environment will be 
decisive. The development process will not gain momentum if the world economy lacks dynamism and stability and is characterized by uncertainty. Nor will it gain momentum if developing countries carry the burden of external debt, if development finance is insufficient, barriers to market access exist, and commodity prices remain low, and terms of trade of developing countries remain unfavorable.

The importance of tourism in macroeconomic figures is so high that the World Economic Forum emphatically said that tourism was responsible for the creation of a very substantial part of jobs in developing countries. Meanwhile, the Sustainable Tourism - Eliminating Poverty Initiative aims to strengthen measures intended at reducing poverty in poor countries, through tourism activities. To this end, institutional coordination at world level is necessary. This international climate makes tourism organizations in our country have a number of preset channels through which they must travel. That is why they enjoy some unique characteristics that we develop in the next lines.

The international economy should provide an enabling international climate for achieving environmental and development goals by promoting sustainable development through trade liberalization. Also, making trade and the environment mutually supportive. In addition, by providing sufficient financial resources to developing countries and addressing the issue of international debt. And finally, encouraging the adoption of macroeconomic policies favorable to the environment and development.

Furthermore, policies and measures aimed at creating an international environment that strongly supports national development efforts are fundamental. International cooperation in this area should be designed to complement and support, not to diminish or subsume, appropriate national economic policies in both developed and developing countries for the world to move towards sustainable development.

Global Compact is an international initiative that promotes the implementation of 10 Universally Accepted Principles to promote Corporate Social Responsibility (CSR) in the areas of Human Rights and Business, Labor Standards, the Environment and Fight against Corruption in the activities and business strategy of the companies. With over 13,000 signatories in more than 145 countries, it is the largest voluntary initiative of corporate social responsibility in the world. Backed by the CEOs of its member companies, the Global Compact is a practical framework for developing, implementing and disseminating corporate sustainability policies and practices, providing its signatories with a wide range of resources and management tools to help them implement Business and sustainable development. Global Compact is considered a framework of action that facilitates the social legitimacy of businesses and markets. Those organizations that adhere to the Global Compact share the conviction that business practices based on universal principles contribute to the creation of a more stable, equitable and inclusive global market and that it fosters more prosperous societies.

The Global Reporting Initiative (GRI) is an independent organization created in 1997 by the convening of the Coalition of Environmentally Responsible Economies (CERES) and the United Nations Environment Program (UNEP). Its mission is to develop and disseminate the Sustainability Reporting Guide, an optional accounting report on sustainability. The GRI has developed the "Guide for the elaboration of a sustainability report", whose first version appeared in 2000, the second in 2002 and the third in 2006. Its mission is to improve the quality, accuracy and usefulness of reports of sustainability to reach a level equivalent to that of financial reports. It is fundamentally based on the implementation of triple bottom line, economic, social and environmental. The GRI counts on the active participation of representatives of human rights organizations, labor rights, research, environmental, corporations, investors and accounting organizations. 


\section{DEFINING CHARACTERISTICS OF THE CURRENT TOURISM ORGANIZATION IN SPAIN}

Spain is one of the main tourist powers of the world, both for the number of visitors it receives and for the income reported by this activity. The consolidation of Spain as a tourist destination dates back to the 1960s, although it has a worthy background in illustrated travelers and the romantics who visited Spain. Since the eighteenth century, but especially throughout the nineteenth century, many travelers travel through Spain, including naturalists and writers. Both of them were impressed by the diversity offered by the nature of Spain, by the exoticism of landscapes reminiscent of Africa, by the survival of Arab and Eastern heritages, by cities and monuments, by types and customs Popular, for banditry, for bullfights, etc.

The tourist model that has been consolidated in Spain has as main characters the international origin of the visitors, its condition of mass tourism and the concrete demand of sun and beach. The countries that send tourists to Spain are mainly members of the European Union. Germany and the United Kingdom stand out, from which almost half of the tourists visit us annually, followed by France, Benelux, Italy and the Scandinavian countries. Spanish tourism achieves the international podium thanks to the richness of its cultural resources, its infrastructures and "the adaptation to the digital consumption habits", according to the agency, which analyzes the holiday industry of 141 countries around the world. Spain has climbed at a high speed in this world ranking, since in the previous edition of 2013 (the study is done every two years), ranked fourth. And in 2011, the eighth.

In Spain the competences in the matter of tourism are transferred to the Autonomous Communities (article 148 of the Spanish Constitution). The central State, therefore, does not have direct competences in tourist matters, although it can make policies that influence the sector in function of other of its attributes: foreign trade, international relations, legislation of professional titles, international promotion, etc.

Many approaches can be used to define a tourist organization today. Based on the different business theories, a common factor that emphasizes all of them is the pursuit of profits. Today, this profit maximization and cost reduction is accompanied by a very strict code of ethics, in which tourism organizations try to give back to society part of these inputs. Therefore, the newest theories are talking about the existence of a new model of social enterprise. According to Manuela Guzmán Raja and Carmen Maria Martínez Franco (2016, pp.5-6), a social enterprise can be defined in the next terms: A matter of great importance is the conceptualization of the scope of entities that could enjoy such qualification. In this regard, the definitions developed throughout the 21 st century, could be included in this field both non-profit entities such as corporations, as long that their main purpose is the pursuit of social benefit. Therefore, what comes is to combine the creation of economic and social value simultaneously, the raison d'être of such entities, using for the achievement of strategic business tools capable of generating surpluses that allow them to refinance, and not depend on donations or subsidies to ensure their survival, achieving its financial sustainability. In summary, social business generates a business process that provides innovative solutions to social problems.

As the last point suggests, tourism organizations today as social enterprises, offering innovative solutions to specific social problems. These solutions can be referred to use the expression outlined by the authors above, in a study that also has been awarded by AECA.

Certainly, tourist organizations have opted for the social commitment, bringing in their business and organizational practices the banner of eco-efficiency, and proclaiming itself as a role model to other companies. 
Following the characteristics of the current tourism organization, it can be cited innovation, which is necessary in the changing scenario. Today, hotel companies move in an environment of continuous change, which is why making continuous innovation will allow them to adapt competitively to the changes and transformations and succeed in business.

Transparency can be another defining characteristic of the companies, since the climate in which is that of corporate responsibility, so that transparency in practice becomes as demand from society to current companies. According to Guzmán Raja and Martínez Franco (2016, p.8): Transparency and visibility for these businesses is essential, mainly because the creation of social value cannot be measured by economic profitability.

Another characteristic - which would not deplete, in any way, all the definitive features - is the commitment to historical time: indeed, the importance of conjugation of competitiveness, efficiency and cost reduction with respect for the environment has made the scenario of social responsibility the forced context for a tourist company to succeed in business. In part, this is because the social awareness that exists, not only public authorities, but also the people - customers of the touristic company -.

Finally - and with no desire of exhaust the characteristics of the current tourism organization - it is imbued with the concept - so in vogue today - of environmental responsibility and forming a constituent part of the Corporate Social Responsibility. This new construct refers to the importance of not generating any negative effect on the environment in which tourism develops.

\section{DESCRIPTION OF THE TOURISM PLAN 2020}

To finish describing the current scenario, it is necessary to explain - albeit so briefly - the Tourism Plan 2020, by the Ministry of Industry, Tourism and Trade (2006) specifically designed to achieve an improvement in the sustainability and competitiveness of the tourism sector.

The objectives of the Tourism Plan 2020 are to increase the social and economic benefits of tourism, to achieve a socio-territorial rebalancing that promotes tourism in new destinations, to improve the quality of the natural and cultural environment, reducing the negative impacts that the Tourist activity. In summary, make public and society aware of the importance of supporting tourism as a guarantee of prosperity and improvement of living conditions.

There are many publications that focus on this issue that are shown next:

1. To achieve a rebalancing of territories through tourism and a de-seasonality of the places. To this end, there are competitiveness plans (which are focused, among other things, to achieve accessibility in the destination), the Senior Tourism Pilot Project in Europe (born by the awareness that currently exists in caring and articulate leisure in elderly population - greater today, because people is in a progressively aging society).

2. Planning and good management of destinations, specifying assessment tools of sustainability.

3. Retraining of tourist destinations classified as obsolete.

4. Other measures.

The Plan is part of the process of modernization of Spain and the great Economic and social transformation that it has experienced in the last 15 years, As a result of its full incorporation into the globalized economy and the European space. Its goal is to achieve that in the 2020, Spanish tourism system is the 
most competitive and sustainable, providing maximum social welfare. Tourism 2020 defines a strategy agreed upon and shared by the public and private agents of the sector for the coming years, thus laying the foundations for preparing and adapting the tourism industry to the changes it faces, in order to enhance and improve its Position in 2020.

In short, the Spanish Tourism Plan 2020, based on the principle of shared leadership, is the beginning of a set of actions that tourism administrations and entrepreneurs of the sector will develop from the commitment to the environment, New technologies and the consideration of people as the main asset of the Spanish tourism sector. In this way, together we will ensure that Spanish tourism is one of the main sources of employment and social welfare.

\section{EMPIRICAL STUDY}

\section{The Position of Spain in the Global Compact and the Global Reporting Initiative Agreement}

The second part of this study is an empirical or analytical study of the situation of Spain in the Global Compact and the Global Reporting Initiative (GRI) agreement, based on the theoretical framework above. As the first thing, it can be said that the GRI Model is a good practice guide that provides support for companies to adopt effective policies about Corporate Social Responsibility and social commitment. That is, according to experts in the field, an enormously powerful analytical tool to achieve good collaboration between all stakeholders. In summary, the goal is to achieve in the companies involved a balance in three ways, economic, social and environmental and, at the same time, they are balanced.

The number of signatory companies of the Global Compact and the number of Spanish companies reporting according to GRI are represented in the table below. As it can be seen in Table 1, the number of Spanish companies' signatories of the Global Compact and the number of Spanish companies reporting according to GRI, have increased progressively from 2002 to 2012.

Table 1. The number of Spanish companies' signatories of the Global Compact and the number of Spanish companies reporting according to GRI

From the data in the table above, it is necessary to extrapolate the number of Spanish companies' signatories of the Global Compact for the coming years. For that, in first place the evolution of these values over the years of study (2002-2012) is shown graphically. Secondly, from this graph a regression function to predict spending in the coming years is constructed.

Note that it has been adjust the values by a fourth degree polynomial function, since the adjustment is quite good (coefficient of determination 0.993).

The regression model shown in Figure 2, can be used to estimate the values of number of Spanish companies' signatories of Global Compact for the coming years, as it is shown in Table 2.

In table below, it can be seen how the values will gradually increase in the coming years, as has happened in the last 10 years exponentially.

If a similar analysis is made for the number of Spanish companies reporting according to GRI, similar results are obtained (as seen in the following charts). 
Table 1. Number of signatories of the Global Compact Spanish companies and number of Spanish companies reporting according to GRI (Garcia Martin, 2014)

\begin{tabular}{|l|c|c|}
\hline & $\begin{array}{c}\text { Number of Spanish companies signatories of the } \\
\text { Global Compact }\end{array}$ & $\begin{array}{c}\text { Number of Spanish companies reporting according } \\
\text { to GRI }\end{array}$ \\
\hline $\mathbf{2 0 0 2}$ & 62 & 7 \\
\hline $\mathbf{2 0 0 3}$ & 109 & 14 \\
\hline $\mathbf{2 0 0 4}$ & 146 & 35 \\
\hline $\mathbf{2 0 0 5}$ & 204 & 61 \\
\hline $\mathbf{2 0 0 6}$ & 350 & 91 \\
\hline $\mathbf{2 0 0 7}$ & 314 & 122 \\
\hline $\mathbf{2 0 0 8}$ & 402 & 132 \\
\hline $\mathbf{2 0 0 9}$ & 522 & 160 \\
\hline $\mathbf{2 0 1 0}$ & 666 & 178 \\
\hline $\mathbf{2 0 1 1}$ & 1.034 & 186 \\
\hline $\mathbf{2 0 1 2}$ & 1.381 & \\
\hline
\end{tabular}

Figure 1. Evolution of Spanish companies' signatories of the Global Compact (2002-2012)

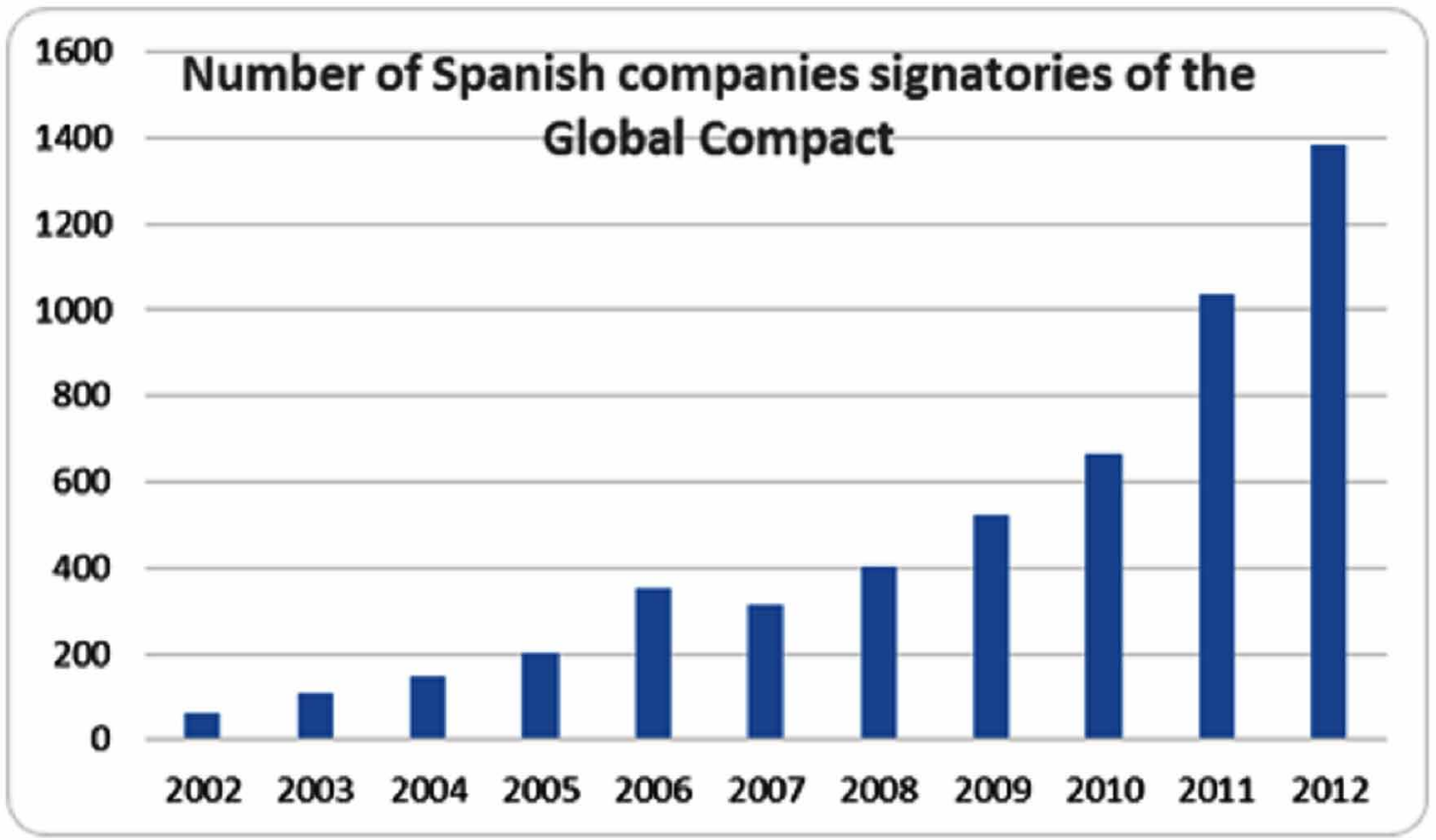


Figure 2. Fourth degree polynomial adjust

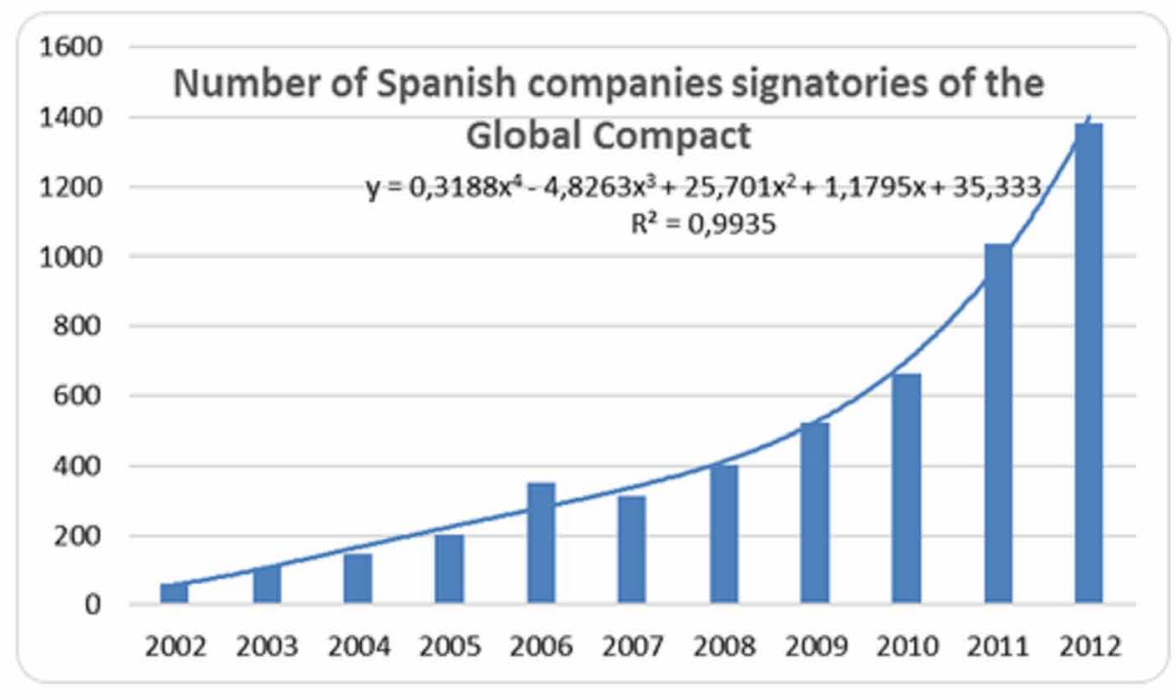

Table 2. Data of Spanish companies' signatories of the Global Compact (2002-2012)

\begin{tabular}{|c|c|c|c|c|c|c|c|c|}
\hline Year & $\mathbf{2 0 1 3}$ & $\mathbf{2 0 1 4}$ & $\mathbf{2 0 1 5}$ & $\mathbf{2 0 1 6}$ & $\mathbf{2 0 1 7}$ & $\mathbf{2 0 1 8}$ & $\mathbf{2 0 1 9}$ & $\mathbf{2 0 2 0}$ \\
\hline Spanish companies & 2.020 & 2.895 & 4.091 & 5.684 & 7.756 & 10.395 & 13.699 & 17.774 \\
\hline
\end{tabular}

\section{The Importance of Tourism Organizations in the Global Compact}

The World Tourism Organization (UNWTO) and the United Nations Global Compact are private sector interlocutors for the achievement of the Sustainable Development Goals (ODS) and the Development Agenda 2030 for what is called for action. This sector is key to the economy and social welfare and has actors who are aware and able to exemplify the true impact of Corporate Social Responsibility (CSR). The Global Compact is the largest voluntary initiative of corporate responsibility and sustainable development in the world, aimed at generating shared value among its members.

Companies in the tourism sector play an important role in transforming the sector's approach and introducing sustainability criteria into its operations. These can promote responsible tourism, which respects the natural, cultural and social environment and promotes the sustainable development of tourist destinations.

Companies are vital in this Global Compact because they express their commitment to work for sustainable development in the hands of leading organizations in the sector with which to enhance their opportunities. The United Nations Global Compact is the largest global public-private partnership for development in which 12,500 companies from 145 different countries come together to promote Ten Principles based on universal declarations and conventions related to human rights, labor standards, the environment and the fight against corruption. 
Figure 3. Evolution of the number of Spanish companies reporting according to GRI (2002-2011)

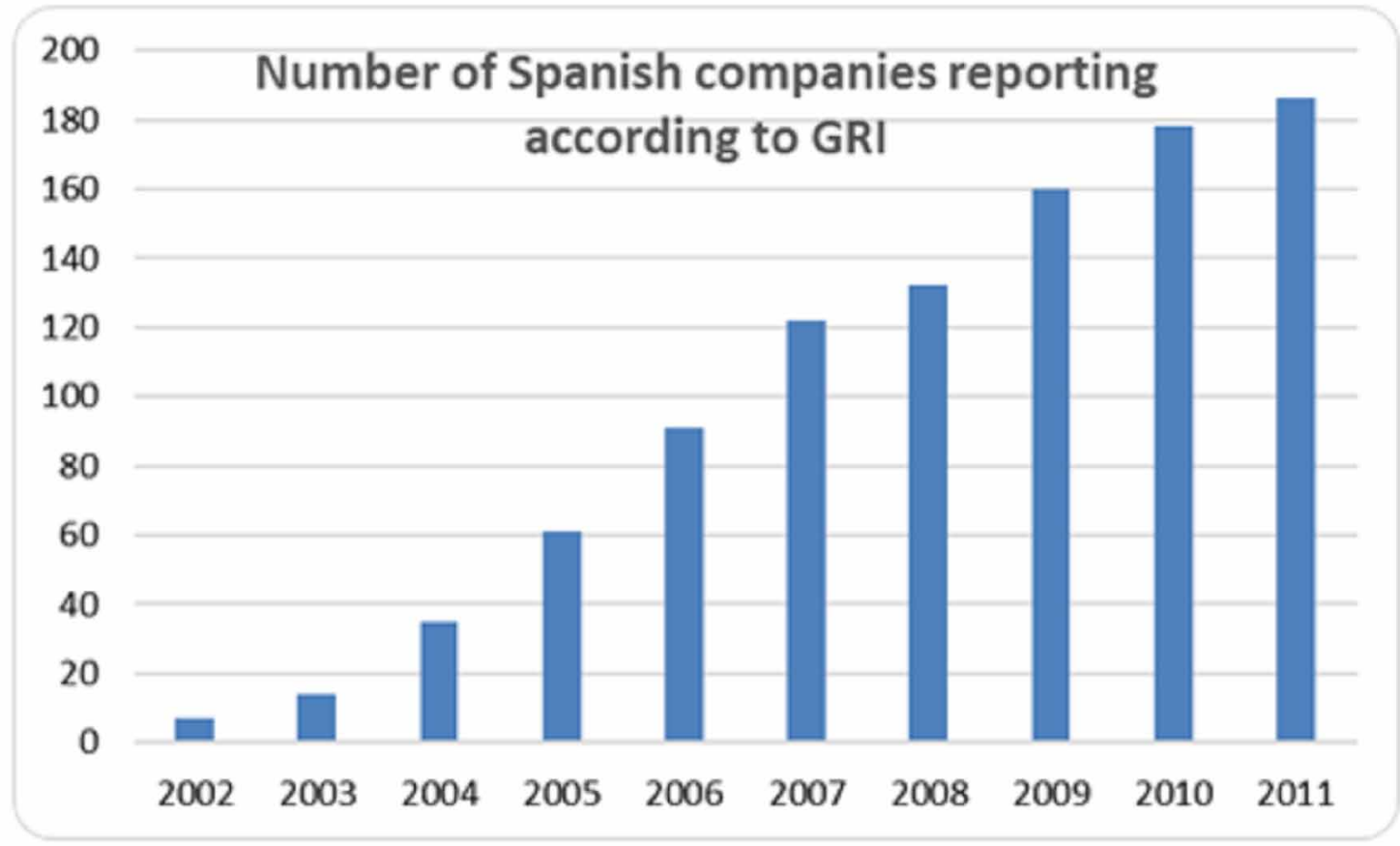

Figure 4. Second degree polynomial adjustment

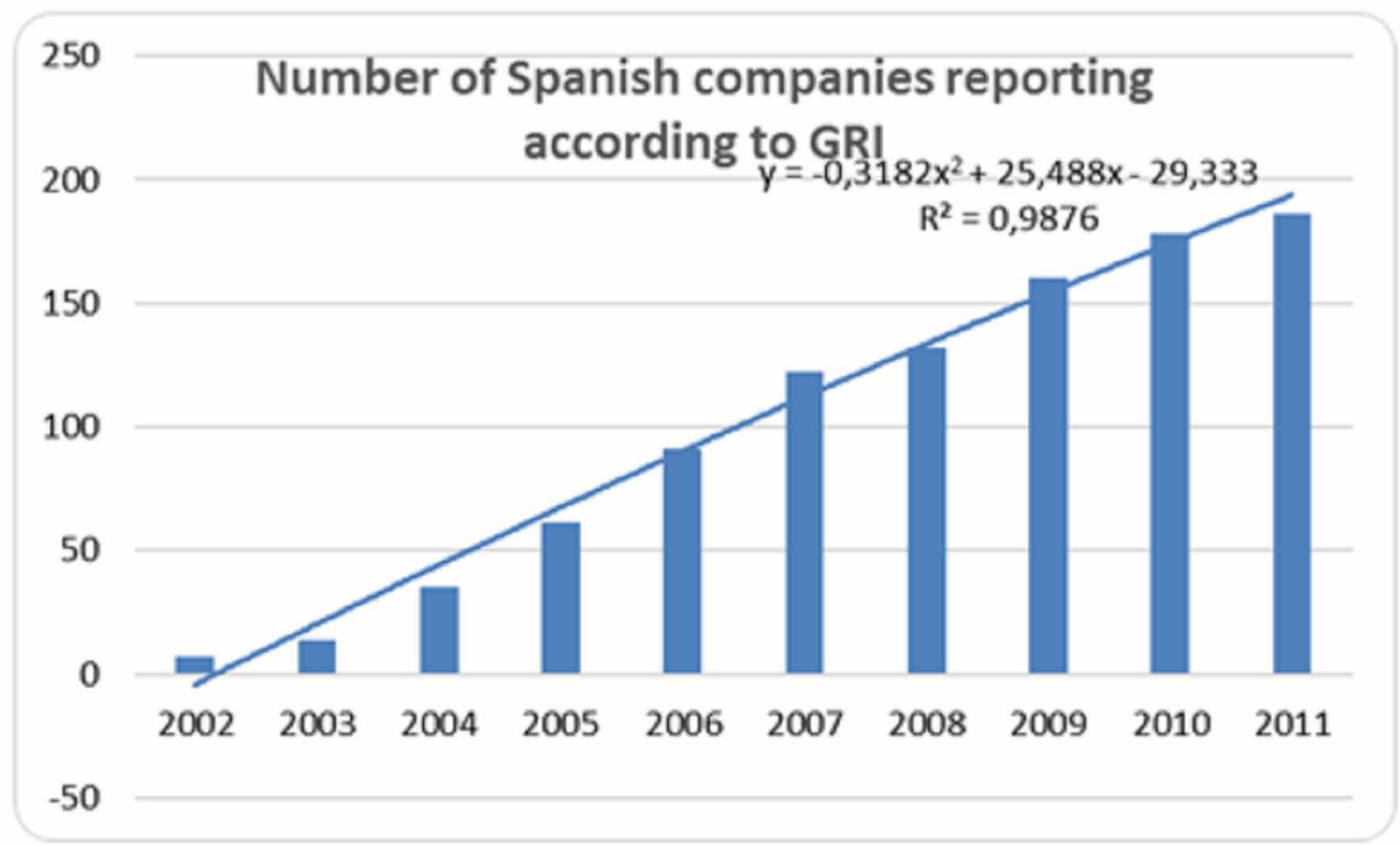


Figure 5. The pillars of sustainability

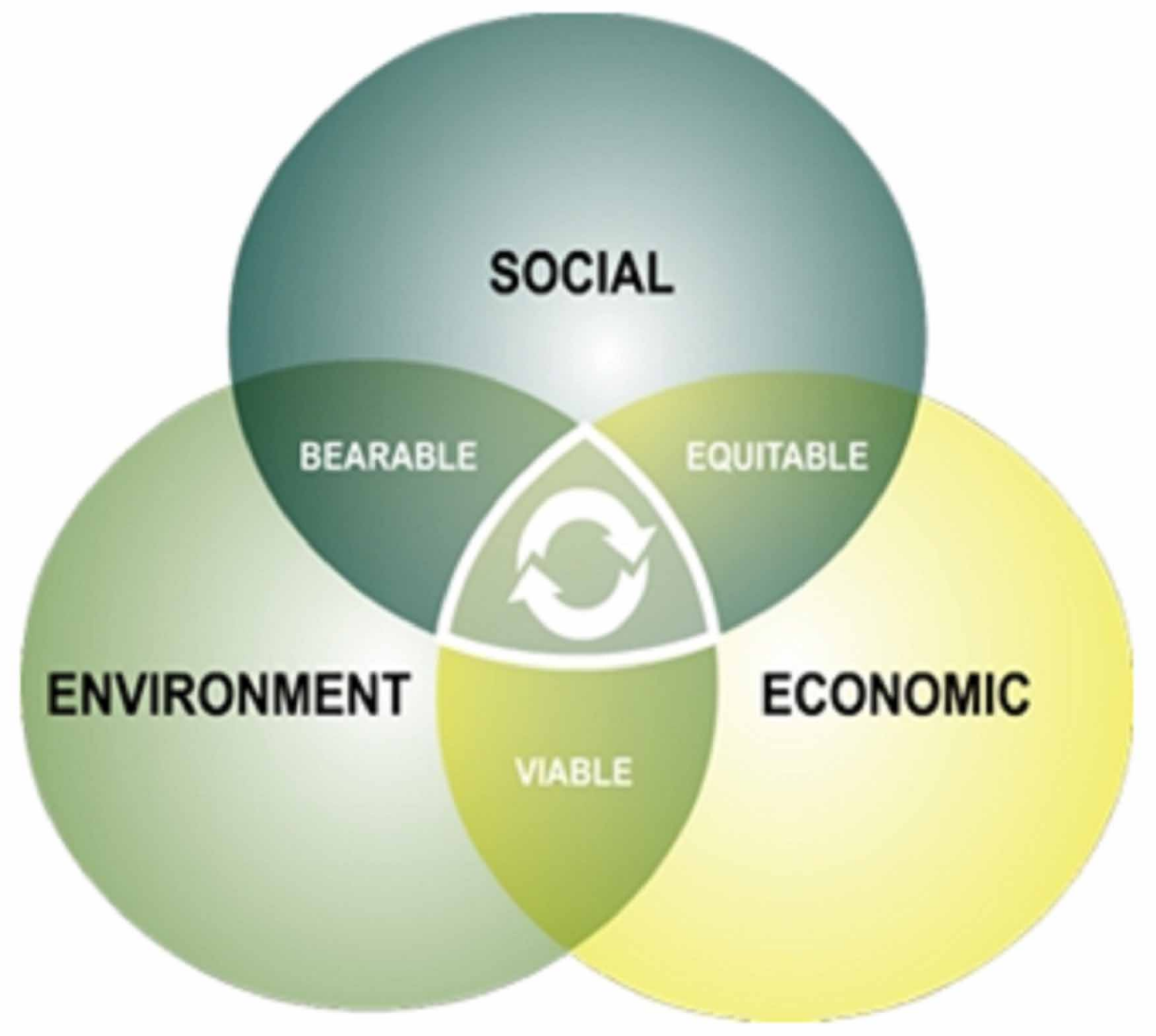

Tourism plays a key role in the EU, because of its economic potential and job creation, as well as its social and environmental implications. Statistics on tourism are not only used for EU tourism policies but also for monitoring regional policy and sustainable development.

As it was advanced at the beginning of this chapter, organizations and hotel and tourism enterprises are set up as a demonstrative example of responsible activity with the environment and socially sustainable practices, establishing itself as a role model. An example of this reality can be the collaboration established by the UNWTO (United Nations World Tourism Organization) and the Spanish Global Compact Network, in which a total of thirteen organizations located in our country - number that is growing right now - participate in the objectives of establishing and solidifying various practices of CSR (Corporate Social Responsibility), aimed, as is well known, to the constant increase of sustainable tourism.

It is important to remark that the working paper entitled "Responsible Tourism: a commitment by all", document that the authors have managed to prepare this chapter, in which a decalogue of good practices 
for hotel and tourism companies in general, aimed to complete the various objectives of sustainable development (specify irrefutably the three pillars of sustainable tourism - economic, environmental and socially -), as set out in the following illustration.

In this way, businesses and tourism organizations contribute not only to their activities, but also the mechanisms of social awareness to create and achieve a more balanced society where preserving the resources of nature and creation an equalitarian society are configured as key objectives. As mentioned in previous lines, are thirteen Spanish companies that are part of the agreement between the World Tourism Organization and the Spanish Network of Global Compact, a reality that, according to the data, will grow and becoming more intense in the upcoming years. In this propitious scenario, it has had much to do the publication of Global Code of Ethics for Tourism and the 10 Principles of the Global Compact. Notice that the chapter addresses issues so important as education, employment and, of course, human rights. It is important to remark the words of the President of the Spanish Global Compact Network, Ángel Pes (2016): This initiative is a pioneer not only by the involvement of the private sector in the Agenda of 2030, but also by the need to involve key players in achieving a sector of responsible and sustainable tourism. To put a challenge of its kind in the third most visited country in the world it offers interesting possibilities to replicate this project globally.

In the case of Spain, thanks to the collaboration agreement reached by the World Tourism Organization (WTO) and the Spanish Global Compact Network, thirteen Spanish companies have joined the commitment to develop corporate social responsibility practices that advocate sustainable tourism. Under the title 'Responsible Tourism: A Commitment for All', the initiative launched on 19 September highlights the role of tourism companies in achieving the Sustainable Development Goals (ODS).

As we finish this article, the twenty-fifth edition of the UN Climate Change Conference is opening in Madrid. The main goal of this convention is to deal with the climate crisis by consensus in order to address the risks involved. This climate summit takes the form of a political forum and includes companies, civil society stakeholders and other social entities with the objective of reducing the effects of climate change. It's basically continuation of the Paris Agreement and the Kyoto Protocol.

Among the most important activities of this major convention is the so-called "Global Climate Action Agenda", which focuses on events carried out by NGOs. In short, this climate summit showcases the huge concern on a global scale when it comes to the environment and sustainability, an issue that fits in with the 2030 Agenda. The 2030 Agenda for Sustainable Development is a decisive action plan resulting from concerns aired by the United Nations, with the key goals being the protection of the environment and people, as inhabitants of 'Mother Earth'.

This Agenda already has somewhat of a tradition, as United Nations member countries met in 2012 to set the MDGs, i.e. the Millennium Development Goals, for the year 2015, which was when a new global agreement on climate change was created. In that sense, on 25 September 2015, the member countries adopted the agreement to implement the 2030 Agenda, which is basically a programme of measures sponsored by the United Nations and encompassing a total of seventeen Sustainable Development Goals that are in turn divided into 169 targets to facilitate compliance. Within these goals and targets, centre stage is given to the poorest or most vulnerable regions and the most fragile population groups. These goals are, in short, pathways to overcome current environmental problems and thus build a more sustainable world from a social, economic and - of course - environmental point of view. Government partnerships and citizen engagement, together with the important work carried out by non-governmental organisations (NGOs), are necessary (but not sufficient) conditions to achieve sustainability. The idea is for the agreed commitments to be fulfilled in a transition from theory to action. In this sense, innovation 
is necessary and paramount, particularly because it influences all industries and all spheres of society today. Innovation is key to fulfilling and cementing these goals, for which it is necessary to take into account the level of progress of every nation across the world. Frank collaboration between the public and private sectors is a very important and decisive incentive for this reality to become more and more plausible. Civil society, as mentioned above, also plays a vital role in this whole process. In short, it's about guaranteeing a prosperous and sustainable world in terms of present and future. We need to learn from past mistakes, so that they don't happen again and so we can constructively guarantee a better world for the generations to come. Not just the environment, but also social equity, employment, justice, protection of the most disadvantaged, healthcare and education are crucial factors to achieve a more prosperous and equitable world.

In the fulfilment of the goals set in the 2030 Agenda which, as we'll recall, is a consensual climate action plan organised and promoted by the United Nations, tourism plays an absolutely vital role, which is an important incentive for corporate social responsibility. Tourism, as an economic activity with a great reach (in the sense that it favours and positively impacts activities such as retail, transport, etc.) plays a decisive role in social development and progress, in the promotion of economic and sustainable development and in the enhancement of peace and harmonious living in the nations receiving tourist flows.

With tourism models having surpassed developmentalist models and formulas, the new branches of tourism lead to decent employment, granting job opportunities to once excluded groups and making tourism activities foster an awareness of being "at the core of self-development". Specifically, the most important contributions made by tourism to job creation are condensed in target 8.9 , which reads as follows: "By 2030, devise and implement policies to promote sustainable tourism which creates jobs, promotes local culture and products".

The important contribution of tourism to the promotion of ethical consumerism is well-known (and has already been mentioned in this article). Sustainable production is linked with ethical consumerism, which triggers and fosters critical and environmentally conscious awareness. Rethinking global tourism, i.e. on a worldwide level, has been key in reaching a consensus of governments and nations to implement joint actions that favour the environment. We have seen the major input of tourism in encouraging local, ethical and artisanal production and in cementing ethical consumerism with the environment, which protects the current generations and guarantees an intact environment for the coming generations. Target $12 \mathrm{~b}$ of SDG 12 underlines the need to - we quote verbatim - "develop and implement tools to monitor sustainable development impacts for sustainable tourism which creates jobs, promotes local culture and products". In harmony with the goal mentioned, let's now look at target 14.7, which reads "By 2030, increase the economic benefits to small island developing States and least developed countries from the sustainable use of marine resources, including through sustainable management of fisheries, aquaculture and tourism".

Respectful formulas of tourism help preserve the oceans, marine resources and all natural ecosystems. If we specifically focus on maritime and coastal tourism, we'll see that many small island states are greatly benefiting from the inputs derived from this type of tourism in terms of economic and social progress. These are also very environmentally friendly activities and always carried out under the parameters set by the cornerstones of sustainability. Only in this way can truly sustainable and inclusive development and growth be achieved. 


\section{CONCLUSIONS}

Tourism is configured as an important activity in the economy of a country, this being especially palpable in the case of Spain, since tourism activities in our country have undergone a major evolution, from very developmental models to other paradigms markedly environmentally respectful and that are very much alive today. It is in this scenario that takes a leading role Corporate Social Responsibility. In this contribution it was analyzed the evolution of tourism businesses in our country. Furthermore, it was explained in detail in this chapter what the current situation is. Notice that, this reality is clearly tinted by Corporate Social Responsibility. Thus, one of the strategic and business lines of hotel and tourist companies in general has been precisely environmental responsibility.

Tourism has become today a model example, i.e., serving as an example for other sectors, the welldoing of business practices and management. In this way, new typologies of tourism have acquired an international reputation, such as "tourism for the poor", characterized by channel towards the most disadvantaged populations an important part of the inputs generated by tourism. The sector has enormous potential for the creation of decent work and the promotion of entrepreneurship, helping to empower disadvantaged groups, in particular young people and women. In addition, tourism promotes exchange between people from different parts of the world, enhancing understanding between cultures and promoting peace between communities and nations. Tourism is, therefore, one of the most dynamic and far-reaching economic sectors.

Many approaches can be used to define a tourist organization today. In Spain, hotel companies come characterized by constant innovation, flexibility, transparency and Corporate Social Responsibility. Today, hotel companies move in an environment of continuous change, making continuous innovation will allow them to adapt competitively to the changes and transformations and succeed in business.

In addition, sustainable tourism contributes to generating long-term benefits, investing in measures to combat deforestation and desertification, to maintain tourist destinations in optimum conditions and to generate a greater flow of visitors and benefits to the environment and local communities. Companies that are committed to sustainable tourism can create programs for tourists focused on how to preserve and care for the environment to help local communities manage their visits in order to obtain the greatest possible benefit with a minimum of risks to their ecosystems, Its biological diversity and its flora and fauna. Responsible production and consumption are also considered key challenges, both in terms of the supply chain of companies in the sector, and in the promotion of patterns of sustainable consumption among tourists. In addition, it is important to preserve the destination and promote sustainable and intelligent cities that benefit the local population and tourists.

The empirical study of the situation of Spain in the Global Compact and GRI agreement over the years of study (2002-2012) was performed. Specifically, regression models were constructed of these cases to predict spending in the coming years. These models shown that the number of Spanish companies' signatories of the Global Compact and the number of Spanish companies reporting according to GRI gradually increase in the coming years.

In this way, it has been seen throughout this chapter that Spain is aware of the importance of tourism and its role in the development model, the short-term successes, and that is the key to real opportunities. Therefore, the country must try to adapt progressively to the structural changes that occur in the global context and that directly affect the tourist market and that condition our competitiveness in the immediate future. These are changes that have to be answered in a creative and innovative way, in the face of the inertia of the past unviable, at least dubious, in the real tourist scenario. 
In the last part of our chapter, it was shown specifically on the contribution of hotel and tourism organizations in sustainable development and Corporate Social Responsibility. In conclusion, companies within the hotel industry are examples to follow of responsible activity with the environment and socially sustainable practices. Promoting sustainable and intelligent cities is fundamental to guarantee destinations that attract tourists and promote the quality of life of local communities. The Sustainable Development Objectives require the construction of strategic alliances between the different actors that have an impact on the sector. In short, they require the commitment of society as a whole.

\section{REFERENCES}

Ayuso, S. (2003). Gestión sostenible en la industria turística. Retórica y práctica en el sector hotelero español (Unpublished doctoral dissertation). Universidad Autónoma de Barcelona, Spain.

Ayuso, S. (2005). Turismo y desarrollo sostenible. Revista Cultural. Ejemplar dedicado a Cultura Sostenible, 40, 101-104.

Ayuso, S., \& Argandoña, A. (2009). Responsible Corporate governance: Towards a stakeholder board of directors? Corporate Ownership and Control, 6(4), 9-19. doi:10.22495/cocv6i4p1

European Commission. (2001). Green Paper: Promoting a European framework for Corporate Social Responsibility. COM(2001)366. European Commission.

European Commission. (2002). Corporate Social Responsibility: A business contribution to Sustainable Development. COM(2002)347. European Commission.

European Commission. (2003). Opinion of the Committee of the Regions on the 'Communication from the Commission to the Council, the European Parliament, the European Economic and Social Committee and the Committee of the Regions - Basic orientations for the sustainability of European tourism'. COM(2003) 716 final. Brussels: European Commission.

Garcia Martin, M. A. (2014). La responsabilidad social corporativa en las entidades públicas y el proceso de reforma de las Administraciones Públicas. Retrieved November 15, 2016 from http://www.pap. minhap.gob.es/sitios/140aniversario/Documents/DEBATEMiguelAngelGarciaMartin.pdf

Guzmán Raja, M., \& Martínez Franco, C. M. (2016). Un nuevo paradigma de negocio: La empresa social. Revista AECA, 102, 5-8.

Henderson, J. C. (2007). Corporate social responsibility and tourism: Hotel companies in Phuket, Thailand, after the Indian Ocean tsunami. International Journal of Hospitality Management, 26(1), 228-239. doi:10.1016/j.ijhm.2006.02.001

Holcomb, J. L., Upchurch, R. S., \& Okumus, F. (2007). Corporate social responsibility: What are top hotel companies reporting? International Journal of Contemporary Hospitality Management, 19(6), 461-475. doi:10.1108/09596110710775129

Llull, A. (2003). Contabilidad medioambiental y desarrollo sostenible en el sector turístico (Unpublished doctoral dissertation). Palma de Mallorca: Govern de les Illes Balears/Conselleria d'Economia, Comerç i Industria. 
Middleton, V. (1998). Sustainable Tourism. A Marketing Perspective. Butterworth-Heinemann.

Ministry of Industry, Tourism and Trade. (2006). Plan Nacional de Adaptación al Cambio Climático. Madrid: Oficina Española de Cambio Climático, Ministry of Industry, Tourism and Trade.

Nicolau, J. L. (2008). Corporate Social Responsibility: Worth-Creating activities. Annals of Tourism Research, 35(4), 990-1006. doi:10.1016/j.annals.2008.09.003

Pes, A. (2016, December). La economía será digital o no será sostenible. Paper presented at the meeting El Protagonismo de las empresas ante la Agenda 2030, Madrid, Spain.

Porter, M. E., \& Van der Linde, C. (1995). Green and Competitive: Ending the Stalemate. Harvard Business Review, 73(5), 120-134.

UNWTO. (1995). Charter for sustainable tourism. Retrieved November 7, 2016 from http://www.eunwto.org/doi/pdf/10.18111/unwtodeclarations.1995.21.13.1

\section{KEY TERMS AND DEFINITIONS}

Eco-Efficiency: The relationship between the value of the product or service produced by a company and the sum of environmental impacts throughout its life cycle.

Ecological Crisis: A situation that arises when the environment of a species or a population undergoes critical changes that destabilize its continuity.

Environmental Responsibility: A damage caused to other species, nature as a whole to future generations, by the actions or non-actions of another individual or group.

Natural Resources: Material goods and services provided by nature without altering the part of the human being and contributing to the welfare and development of society directly (raw materials, minerals, food) or indirect.

Social Responsibility: Burden, commitment, or obligation of members of a society either as individuals or as a member of a group, both with each other and for society as a whole.

Sustainability: The balance of a species with the resources of its environment. Describes how biological systems remain diverse, material, and productive over time.

Tourism: Trips and stays made by people in places other than their usual environment within a period of less than 365 days, for leisure, business, or other reasons. 